\title{
A tribute to Associate Professor Susan Sayers (15 August 1943-22 March 2016)
}

\author{
G. R. Singh* \\ Menzies School of Health Research, Child Health Division, Menzies School of Health Research, Brinkin, NT, Australia
}

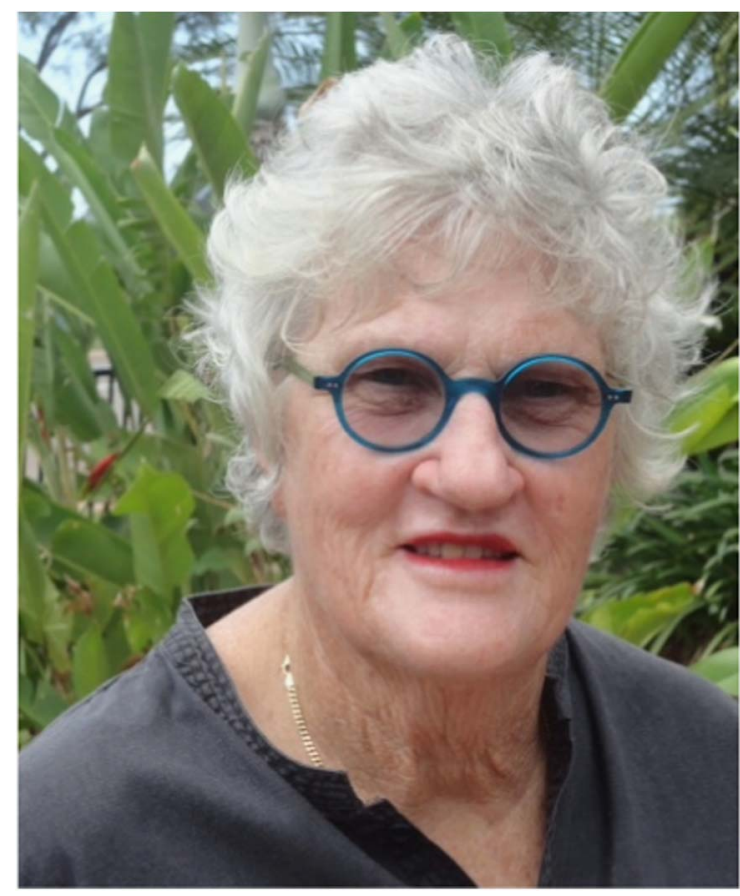

It is with great sadness that we inform you of the passing of Susan Sayers on 22 March 2016 after a short battle with cancer.

She was one of the earliest proponents of Developmental Origins of Health and Disease $(\mathrm{DOHaD})$ research in Australia and bravely tackled one of the greatest challenges facing the Australian and New Zealand $\mathrm{DOHaD}$ community, that of the effects on Australian Aboriginal people.

Associate Professor Sayers is best known as the founder of the Australian Aboriginal Birth Cohort (ABC) Study. The study commenced in 1987 and involves 686 babies born at Royal Darwin Hospital, the $\mathrm{ABC}$ has been followed up over the subsequent 28 years in 40 remote and urban communities across northern Australia. She was to see the study gain credibility over this time to be recognized as the largest and long running cohort of Indigenous people. In recognition of her remarkable contribution, in 2013 she was awarded the Menzies School of Health Research's highest honour, the Menzies Medallion.

In 1977, Sue Sayers was one of the first group of graduates of a newly recognized paediatrics sub-specialty, neonatology and perinatology. Over 40 years, predominantly based at Menzies and Royal Darwin Hospital, Sue pursued a career as a clinician and researcher. Since 1987 Sue has conducted her research working in an honorary capacity, without any salary.

In recent years, past the age where many might have retired, Sue conceived new research ideas and approaches to community engagement in research. She was the driving force behind the HealthLAB; an interactive and educational health programme in a mobile laboratory, which travels to all corners of the Northern Territory of Australia. The HealthLAB has been a particularly useful tool for engaging young Territorians to learn about their own health.

Sue will be remembered for her enthusiasm, dedication and commitment. She was quick to take up new ideas and follow them through. She enjoyed sports, was a dedicated cyclist and a vocal supporter of her Australian Football League team, the Geelong cats. She was very proud of her 'chooks', whose eggs won awards at the Royal Darwin Show. She was very brave and cheerful throughout her illness. She took the time to meet with people as she said this gave her an opportunity to say goodbye.

She touched and inspired everyone around her and her presence will be very much missed.

*Address for correspondence: G.R. Singh, Child Health Division, Menzies School of Health Research, PO BOX 41096, Casuarina, NT, Brinkin, Northern Territory, 0810, Australia.

(Email: Gurmeet.Singh@menzies.edu.au) 